\title{
Effect of Instant Controlled Pressure Drop (DIC) treatment on the detection of nuts by Real Time PCR
}

\author{
Africa Sanchiz ${ }^{1}$, Carmen Cuadrado ${ }^{1}$, Joseph Haddad ${ }^{2,3}$ and Rosario Linacero, ${ }^{4}$ * \\ 1 Food Technology Department, SGIT-INIA, Ctra. La Coruña Km. 7.5, 28040 Madrid, Spain; \\ africa.sanchiz@inia.es_(A.S.); cuadrado@inia.es (C.C.) \\ 2 Laboratory Engineering Science for Environment (UMR 7356 CNRS), La Rochelle University, Avenue \\ Michel Crepeau, 17042 La Rochelle, France \\ 3 Food Science and Technology Department, Faculty of Agriculture; Lebanese University; Dekweneh - \\ Beirut (Lebanon); j.haddad@ul.edu.lb (J.H.) \\ 4 Genetics, Physiology and Microbiology Department, Biology Faculty, Complutense University, 28040 \\ Madrid, Spain charolin@ucm.es (R.L.) \\ * Correspondence: charolin@ucm.es; Tel+34-913944849
}

\begin{abstract}
Tree nuts show nutritional properties and human health benefits. However, they contain allergenic proteins, which make them harmful to the sensitive population. The presence of tree nuts on food labelling is mandatory and, consequently, the development of suitable analytical methodologies to detect nuts in processed foods is advisable. Real-time PCR allowed a specific and accurate amplification of allergen sequences. Some food processing methods could induce structural and/or conformational changes in proteins by altering their allergenic capacity, as well as produce the fragmentation and/or degradation of genomic DNA. In this work, we analysed by means of Real-time PCR, the influence of pressure and thermal processing through Instant Controlled Pressure Drop (DIC) on the detectability of hazelnut; pistachio and cashew allergens have been tested. The detection of targets in hazelnut, pistachio and cashew (Cor a 9, Pis v 1 and Ana o 1, respectively) is affected by the treatment, in different extent depending on the tree nut. Results are compared to those previously obtained by our group in the analysis of different treatments on the amplificability of the same targets. Reduction in amplificability is similar to that reported for some autoclave conditions. Our assays might allow detecting up to $1000 \mathrm{ppm}$ of hazelnut, pistachio and cashew flours after being submitted to DIC treatment in food matrices.
\end{abstract}

Keywords: Real time PCR; tree nuts; allergen detection; processed foods; thermal processing; pressure processing; DIC processing

\section{Introduction}

Food allergy is a worldwide health concern that affects around $2 \%$ of the population, reaching $8 \%$ in children [1]. The most common foods associated with food allergy are fish, peanuts, soybean, milk, eggs, crustacean, wheat and tree nuts. Tree nuts are often responsible for severe and even lethal reactions on sensitised patients [2] and, according to the European regulation, they are one of the 14 allergenic ingredients whose presence must be indicated on the food label (EU 1169/2011). Until the date, there is no treatment for food allergies, so patients must avoid any contact and consumption of allergenic ingredients. Thus, available sensitive and specific detection methods of hidden allergens in foods are essential in order to protect sensitised individuals and comply with current regulations. Enzyme Linked Immunosorbent Assay (ELISA) is the most used methodology for direct detection of proteins from specific foods, as well as other immunoassays, as lateral flow. Alternatively, DNAbased methodologies have been developed in the last years for many tree nuts as indirect detection approaches, especially Real-time PCR, due to its sensitivity and specificity. In the last years, other trends in food allergen detection include biosensors, (especially immunosensors and genosensors) 
that resulted to be advantageous for the development of lab-on-a-chip systems, allowing the fast, sensitive and inexpensive analysis of samples [3].

Most tree nut allergens are identified as seed storage proteins such as vicilins, legumins and albumins [4]. Hazelnut allergy represents an important health problem in industrialised countries because of its high prevalence and severity. Several hazelnut allergens are characterised, such as Cor a 1 (Bet v 1 family), Cor a 2 (profilin), Cor an 8 (lipid transfer protein, LPT), Cor a 9 (11S globulin), Cor a 11 (vicilin-like protein), Cor a 12, Cor a 13 and Cor a 14 (2S albumins). Cashew nuts are responsible for serious allergic reactions in sensitive patients, frequently involved in anaphylactic responses [5]. Three major allergens have been described: Ana o 1 (7S vicilin), Ana o 2 (11S globulin) and Ana o 3 (2S albumin). Finally, five allergens are characterised in pistachio. Pis v 1 (2S albumin), Pis v 2 and 5 (11S globulin), Pis v 3 (7S vicilin) and Pis v 4 (SOD) [6].

Foods, including tree nuts, are frequently submitted to thermal and non-thermal processing in the food industry, to improve organoleptic properties or ensure safety. Roasting, boiling, baking or frying are common thermal treatments applied in the food industry. Some of these thermal treatments are applied in combination to pressure, as autoclave, resulting importantly efficient for immunoreactivity reduction of several tree nuts, in particular conditions [7-9]. Instant Controlled Pressure Drop (DIC) [10] is also a pressure-based thermal treatment that has been applied to foods trying to diminish their allergenic potential, especially in legumes [11,12]. Many studies have demonstrated that certain thermal treatments might be useful to diminish the allergenic potential of nuts, influencing allergen structure $[13,14]$. The solubility of allergenic proteins is often affected by thermal treatments [15], and as a consequence, the performance of protein-based detection methods, as ELISA, might be highly compromised. Moreover, cross-reactivity is often referred to in this technique [16]. DNA molecules are normally more stable to chemical and thermal processing and can be more efficiently extracted from raw and processed samples. For this reason, DNA based assay is becoming a promising alternative to proteins for allergen detection in highly processed food samples [17]. To develop and validate the suitable performance of a Real-time PCR assay for food allergen detection, the influence of thermal and non-thermal treatments on the target isolation and amplification should be analysed [18]. Particularly for tree nuts, Real-time PCR has resulted in a specific, reliable and sensitive method for the detection of many allergens [3].

Previously to this study, the development and validation of Real-time PCR methods for pistachio, cashew and hazelnut were performed and published [19-21]. In the three works, allergencoding genes were selected as target (Pis $\mathrm{v} 1$ for pistachio, Ana o 1 for cashew and Cor a 9 for hazelnut). Moreover, detection of target Pis $\mathrm{v} 1$, Ana o 1 and Cor a 9 and the influence on its amplification have been analysed in different samples processed by boiling, autoclave, roasting or high-hydrostatic pressure (HHP). In this work, we have performed binary mixtures (control and treated flours in wheat flour) and the same DNA isolation method for all the samples. We tested the effect of a specific thermal and pressure treatment, Instantaneous controlled pressure-drop (DIC), on the amplificability and performance of three validated Real-time PCR systems, using the same published primers and probes.

\section{Materials and Methods}

\subsection{Plant material}

Three nut seeds have been used in this study: hazelnut, pistachio, and cashew. Pistachio (Pistachia vera Kerman) and hazelnut (Corylus avellana, Negreta) were obtained from the Germoplasm Bank of Institut de Recerca i Tecnologia Agroalimentaries (IRTA-Mas de Bover, Tarragona, Spain), whereas cashew nuts (Anacardium occidentale, type 320) were provided by Productos Manzanares S.L. (Cuenca, Spain).

\subsection{Instantaneous Controlled Depressurization Treatment (DIC)}

Whole cashew, peanut, pistachio and hazelnut seeds were subjected to controlled Instantaneous Depressurization (DIC) treatment, performed at the La Rochelle University (LaSiE). DIC treatment 
was carried out following a factorial experimental design previously described [10]. In this experiment, the moistened whole nuts are placed in a processing chamber and exposed to steam pressure $(7 \mathrm{bar})$ at high temperature (up to $\left.170^{\circ} \mathrm{C}\right)$, over a short time (120 seconds). An instant pressure drop towards a vacuum at about 50 mbar follows this high-temperature-short time stage. This abrupt pressure drop, at a rate $\Delta \mathrm{P} / \Delta \mathrm{t}$ higher than $5 \mathrm{bar} \mathrm{s}^{-1}$, simultaneously provokes an autovaporization of a part of the water in the product, and an instantaneous cooling of the products, which stops thermal degradation.

\subsection{Binary mixtures}

Untreated and DIC treated nut seeds were ground with a kitchen robot (Thermomix 31-1, Vorwerk Elektrowerke, GmbH \& Co. KG, Wüppertal, Germany) and defatted with n-hexane (34 $\mathrm{ml} / \mathrm{g}$ ) for 4 hours, following by air-drying. Flours were passed through a $1 \mathrm{~mm}$ mill and stored at $4^{\circ} \mathrm{C}$ until use.

Several points of binary mixtures $(10,100,1000,10000,100000 \mathrm{mg} / \mathrm{kg})$ were performed by mixing known amounts of treated defatted nut flour (from Kerman pistachio variety, type 320 cashew and Negreta hazelnut variety) in spelt wheat (Triticum spelta L.) flour, in a final weight of $25 \mathrm{~g}$. The mixture containing $10 \%$ of each nut $(100.000 \mathrm{mg} / \mathrm{kg}$ ) was prepared by adding $2.5 \mathrm{~g}$ of the nut flour to $22.5 \mathrm{~g}$ of spelt wheat flour, and followed by 10-fold dilutions, homogenizing with the kitchen robot. Moreover, for hazelnut, binary mixtures of DIC treated flours were also performed in peanut defatted flour, in order to mimic the conditions described in our previous paper, taken as reference for this nut [21].

\subsection{DNA extraction and conventional PCR}

Isolation of genomic DNA from nut flours was performed as previously described [17, 20]. Briefly, $100 \mathrm{mg}$ of defatted flour were homogenised in $1 \mathrm{ml}$ of Cetyl trimethylammonium bromide (CTAB) with $1 \%$ of polyvinylpyrrolidone (PVP) and $4 \mu \mathrm{l}$ of $25 \mathrm{mg} / \mathrm{ml}$ RNAse, and were incubated at $65^{\circ} \mathrm{C}$ for $30 \mathrm{~min}$, shaking each interval of 10 minutes. The addition of $800 \mu \mathrm{l}$ of chloroform, mixing, and centrifugation at $13000 \mathrm{rpm}$ for 10 minutes were performed. After taking $800 \mu \mathrm{l}$ of the aqueous supernatant, genomic DNA was obtained following the instructions from the DNeasy Power Plant DNA isolation kit (Qiagen, Hilden, Germany) and eluted in $100 \mu \mathrm{l}$ of $10 \mathrm{mM}$ Tris pH 8.0. At least two different DNA isolations were carried out. The quantity and quality of the extracted DNA were evaluated on $0.8 \%$ TBE agarose gels and using a Nanodrop ND-1000 spectrophotometer (ThermoFisher, Waltham, MA, USA), taking into account the values obtained by measuring absorbance at 230, 260 and $280 \mathrm{~nm}$. We also used DNA obtained in our previous studies [19-21], from other sequenced varieties of hazelnut (Pauetet, Tonda and Sant Giovanni), pistachio (Aeguina, Mateur and Sirora) and cashew (Embrapa 50, BRS 189, BRS 274 and CCP06).

Positive amplification of all samples was tested by PCR using universal eukaryotic primers for $18 \mathrm{~S}$ described elsewhere (forward 5'- CGCGAGAAGTCCACTAAACC-3', reverse 5'CCTACGGAAACCTTGTTACGA-3') [22]. These reactions were carried out in $20 \mu \mathrm{l}$, containing $25 \mathrm{ng}$ of DNA, $250 \mathrm{nM}$ of each primer and 1XFastStar PCR Master Mix (Biotools, Loganholme, Australia). SensoQuest LabCycler (Progen Scientific Ltd, London, UK) was programmed with an initial denaturation step at $95{ }^{\circ} \mathrm{C}, 5 \mathrm{~min}$, followed by 35 cycles of denaturation at $94{ }^{\circ} \mathrm{C}$ for $1 \mathrm{~min}$, annealing at $60{ }^{\circ} \mathrm{C}$ for $30 \mathrm{sec}$ and elongation at $72{ }^{\circ} \mathrm{C}$ for $45 \mathrm{sec}$, and a last step at $72{ }^{\circ} \mathrm{C}$ for $5 \mathrm{~min}$.

\subsection{Targets, primer design and Real-time PCR conditions}

Primers were designed in allergen-coding regions of hazelnut, pistachio and cashew, being conserved among the different varieties (Figure S1), and targets were selected in the Cor a 9, Pis v 1 and Ana o 1 allergen-coding sequences, respectively [19-21]. After that, the performance of primers and probes was assayed, regarding specificity, sensitivity and reaction efficiency. Sequences, final assayed, conditions and amplicon size of primers and probes used in the Real-time PCR assays are summarised in Table 1. 
Primers for Cor a 9 allergen-coding sequence were used previously by our group [21], where a real-time PCR assay based on Sybr Green detection method was performed with good results for this target. For the study we present here, a hydrolysis probe has been designed in order to standardize with the rest of the assays and as an attempt of improving the sensitivity of the method. In pistachio and cashew, Real-time PCR-based detection methods were recently published by our group [19, 20], selecting Pis v 1 and Ana o 1 targets respectively. In these cases, a Locked Nucleic Acid (LNA, Roche, Basel, Switzerland) probe and a hydrolysis probe were designed and used for pistachio and cashew detection, respectively.

Table 1. Primers and probes sequences used for Real-time PCR assays.

\begin{tabular}{|c|c|c|c|c|c|}
\hline $\bar{z}$ & Name & Sequence $\left(5^{\prime} \rightarrow 3^{\prime}\right)$ & $\begin{array}{c}\text { Final concentration } \\
\text { (nM) }\end{array}$ & $\begin{array}{l}\text { Length } \\
\text { (bases) }\end{array}$ & $\begin{array}{l}\text { Amplicon } \\
\text { size }\end{array}$ \\
\hline \multirow{3}{*}{ 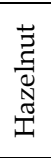 } & Cor a $9 \mathrm{fw}$ & GTCAAAGTGGAAGGCAGGCTT & 250 & 21 & \multirow{3}{*}{101} \\
\hline & Cor a $9 \mathrm{rv}$ & TCCCGCTCTTGCTCACTCTC & 250 & 20 & \\
\hline & $\begin{array}{l}\text { Cor a } 9 \\
\text { probe }\end{array}$ & 6FAM-ATGGGAGCGACAGGAGAGACAAGAG-BHQ1 & 100 & 26 & \\
\hline \multirow{3}{*}{  } & Pis $\mathrm{v} 1 \mathrm{fw}$ & GGCAAAGCTCGTACTTCTCCT & 250 & 21 & \multirow{3}{*}{81} \\
\hline & Pis v $1 \mathrm{rv}$ & TCCACAGTAGCGCGGTAGAT & 250 & 20 & \\
\hline & Pis $v 1$ probe & 6FAM-GACGGAAG-BHQ1 & 100 & 8 & \\
\hline \multirow{3}{*}{$\begin{array}{l}\frac{3}{0} \\
\frac{\tilde{D}}{0} \\
\tilde{J}\end{array}$} & Ana o $1 \mathrm{fw}$ & AGAAAGGACGGGAACGAGAG & 250 & 20 & \multirow{3}{*}{65} \\
\hline & Ana o $1 \mathrm{rv}$ & TTCATCAACGCCACCAGTT & 250 & 19 & \\
\hline & $\begin{array}{l}\text { Ana o } 1 \\
\text { probe }\end{array}$ & 6FAM-ATGAGGAGGAAGAAGAAGAATGGG-BHQ1 & 100 & 24 & \\
\hline
\end{tabular}

Reactions of amplification were performed in a 7900HT Fast Real-Time PCR (Applied Biosystems, CA, USA). In a final volume of $20 \mu \mathrm{l}, 10 \mu \mathrm{l}$ of TaqMan ${ }^{\circledR}$ Gene Expression Master Mix (Applied Biosystems, CA, USA), $0.25 \mu \mathrm{M}$ (for cashew, pistachio, and hazelnut) or $500 \mu \mathrm{M}$ (for peanut) of each primer, $0.1 \mu \mathrm{M}$ (for cashew, pistachio, and hazelnut) or $0.2 \mu \mathrm{M}$ (for peanut) of each probe, and $5 \mu \mathrm{l}$ of DNA at different concentrations are added. Final $250 \mathrm{ng}$ of DNA from untreated and treated binary mixtures in spelt wheat and $25 \mathrm{ng}$ of pure DNA from the nuts and wheat were amplified.

Reactions were run under the following cycling conditions: an initial $10 \mathrm{~min}$ step at $95{ }^{\circ} \mathrm{C}$, followed by 40 cycles of denaturation at $95^{\circ} \mathrm{C}$ for $15 \mathrm{~s}$ and primer annealing and elongation at $60^{\circ} \mathrm{C}$ for $1 \mathrm{~min}$. At least two technical replicates and two non-template controls (NTC) were analysed in each plate. Standard curves were obtained with the cycle threshold $(\mathrm{Ct})$ from 10-fold serial dilutions of genomic DNA and from binary mixtures of nut seeds flour in spelt wheat. The efficiency of the reaction was calculated from the slope from those standard curves (10(-1/slope)- 1$)$, either Ct vs log DNA concentration or Ct vs log quantity of each nut flour.

\section{Results and Discussion}

The influence of DIC treatment on the detectability of target from hazelnut, pistachio, and cashew has been analysed. To determine this, the performance of the reaction was analysed in samples containing known amounts of nut flour in a matrix of Triticum spelta. In the case of hazelnut, binary mixtures were carried out also in peanut defatted flour, to mimic the conditions previously performed by Iniesto and collaborators [21].

\subsection{Effect of DIC treatment on hazelnut detectability}

To test the influence of DIC (instantaneous controlled pressure drop) treatment, based on high pressure and temperature for a very short time on the hazelnut allergen detection by Real-time PCR, Cor a 9 allergen-coding sequence was the selected target, similar to the study published by Iniesto and collaborators [21]. Differently to that work, a hydrolysis probe was designed, using the same primer sequences (Table 1), in order to homogenize the three described strategies. The specificity of these primers was already tested [21] and the probe usually confers an increase in the specificity of the method. The standard calibration curve was made with a serial dilution of hazelnut pure DNA from $2500 \mathrm{pg}$ to $2.5 \mathrm{pg}$, obtaining suitable efficiency in the curve (almost 91\%) and correlation 
coefficient $\mathrm{R}^{2}$ (Figure 1A). The LOD absolute was obtained using the analysis of this curve, achieving a LODabs of $25 \mathrm{pg}$. Furthermore, as described before, two binary mixtures with a known amount of hazelnut flour were prepared, one with T. spelta wheat flour and other with defatted peanut (Arachis hypogaea) flour. Standard calibration curves were built with Ct values against the log of the hazelnut quantity ( $10^{5}$ to $10 \mathrm{mg} / \mathrm{kg}$ or $\mathrm{ppm}$ ). Parameters of both curves were within the proper criteria (efficiency of $90.85 \%$ and $109.50 \%$ and $\mathrm{R}^{2}$ higher than 0.990 for untreated hazelnut in wheat and peanut matrices respectively) (Figure 1B) [23]. In these assays, curves maintained the linearity up to $100 \mathrm{ppm}$ in the mixtures made in peanut and up to $10 \mathrm{ppm}$ in those made in wheat (but only in half of the replica). The practical LOD, which is calculated with these standard curves was $100 \mathrm{ppm}$ (since more than $95 \%$ of the replica were positive), in contrast to $1 \mathrm{ppm}$ obtained by the authors using the intercalant dye Sybr Green as detection chemistry [17]. However, the $\mathrm{Ct}$ values were not delayed in this assay compared to the published one.
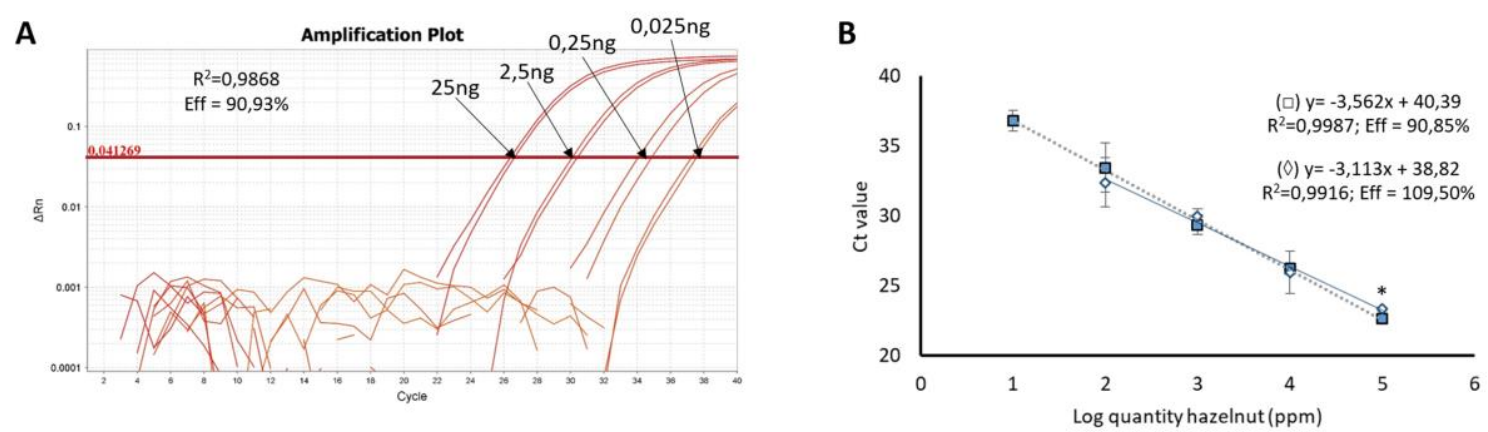

Figure 1. Performance of the amplification reaction for the detection of Cor a 9 target. A) Amplification plot of the calibration curve made from a serial dilution of DNA from Negreta hazelnut variety. B) Standard calibration curve built with DNA from binary mixtures of a known amount of hazelnut in wheat $(\square)$ or peanut $(\diamond)$, representing the log of the $\mathrm{ppm}(\mathrm{mg} / \mathrm{kg})$ of the nut in the wheat/peanut matrix vs $\mathrm{Ct}$ value. *Significant differences among $\mathrm{Ct}$ values in the same spiked level between matrix in wheat and peanut $(\mathrm{p}<0.05)$, $\mathrm{t}$-student unpaired test.

Processing can provoke DNA degradation in different degrees, so these Real-time PCR methods should be able to reach suitable sensitivity, not only in raw samples, but also in treated ones [24]. In order to establish the real influence of any processing, many authors have supported the necessity of analysing the same kind of model mixtures in control and treated samples [25]. For this reason, binary mixtures were also made with DIC treated flours in wheat or peanut flour.

The influence of this treatment, DIC $7 \mathrm{~b} 120 \mathrm{sec}$, on Cor a 9 detection in both binary mixtures is shown in Figure 2A and B. In 10\%-containing spiked level, Ct has delayed around 13 cycles compared to untreated sample, and detection of Cor a 9 target is difficult in mixtures with less concentration of hazelnut, being impossible in mixtures with less than 1000 ppm (Figure 2 and Figure S2). All Ct values of treated samples were higher than the obtained in samples with $10 \mathrm{ppm}$ of untreated hazelnut, and they did not follow a linear regression. This decrease in the Cor a 9 detectability is similar to the exerted by autoclave treatment and described by Iniesto et al [21]. 
A

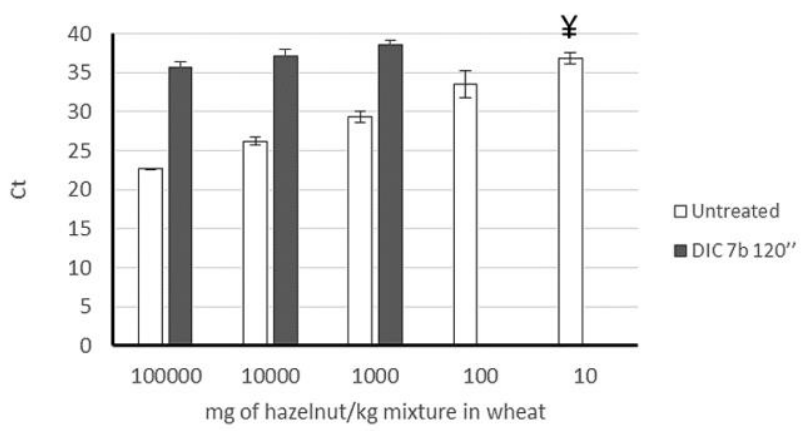

B

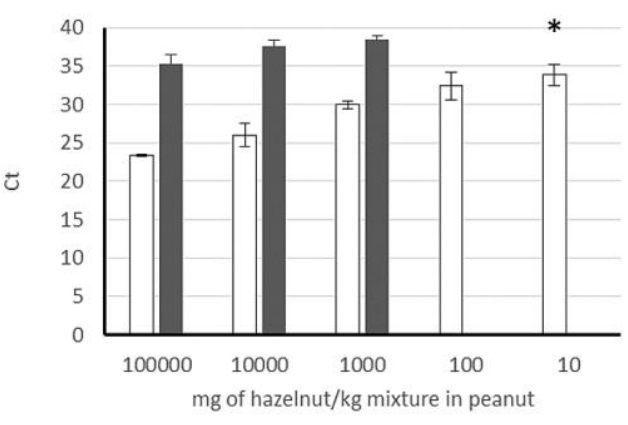

Figure 2. Amplification of Cor a 9 target in untreated (white column, $\mathrm{N}=8$ ) and treated (black column, $\mathrm{N}=10$ ) mixtures in wheat (A) or peanut (B) matrices, representing the quantity of hazelnut in $\mathrm{mg} / \mathrm{kg}$ of mixture vs $\mathrm{Ct}$ value. $¥ \mathrm{Ct}$ signal only in $50 \%$ of the replica. *out of the calibration curve.

Iniesto et al [21] subjected hazelnut nuts to roasting, autoclaving at different conditions, and high-pressure treatments (HHP). DNA was isolated directly from the treated flours, observing that roasting and autoclaving dramatically reduced the extraction yield (in quantity and quality) compared to control, as well as the capacity of the method for detecting any of the tested targets (Cor a 9, Cor an 11 and Cor a 13). This effect was not observed when hazelnut was subjected to HHP processing, where high pressure but no heat is applied. In the present study, analysis of the effect of the treatment applied in this study, DIC $7 \mathrm{~b} 120 \mathrm{sec}$, was based on the preparation of binary mixtures in the same way as the control. Consequently, a comparison between our results and the previous data from Iniesto et al for hazelnut detection is not feasible; however, the effect of DIC treatment on Cor a 9 detectability seems to be very similar to that observed with autoclaving at $138^{\circ} \mathrm{C}$ [21].

The in vitro immunoreactive capability of hazelnut after being subjected to some treatments as HHP and autoclaving has been previously analysed [26]. Recently, Cuadrado et al [13] found that HHP treatment applied on hazelnut and almond nuts did not affect its immunoreactivity detected by Western blotting. Regarding treatment applying, not both pressure and heat, as autoclaving, the effect was drastic; any allergen was possible to be detected after specific conditions of autoclaving. However, as far as we know, the effect of DIC treatment on the IgE/IgG binding capacity of hazelnut allergens has not been studied.

\subsection{Effect of DIC treatment on pistachio detectability}

In the case of pistachio, the preparation of the binary mixtures in wheat, the DNA isolation method, and the amplification reaction were performed as described by Sanchiz and collaborators [19]. The same primers and LNA probe (Table 1) have been used on this occasion, targeting the sequence Pis v 1 , coding for an allergenic $2 S$ albumin. Using the analysis of DNA curves made with serial dilutions of pure nut DNA, from $2500 \mathrm{pg}$ to $2.5 \mathrm{pg}$, the LODabs was obtained, achieving $2.5 \mathrm{pg}$. Curves also showed good performance taking into account two parameters, $\mathrm{R}^{2}(0.996)$ and efficiency $(91.52 \%)$ (Figure 3A). The performance of the curves analysing untreated DNA from binary mixtures containing different amount of pistachio flour was in concordance to the obtained previously $(\mathrm{N}=8)$, regarding efficiency and $\mathrm{R}^{2}$, as well as the practical LOD and limit of quantification (LOQ), both 10 ppm or $\mathrm{mg}$ of pistachio/kg of the mixture (Figure $3 \mathrm{~B}$ ). 

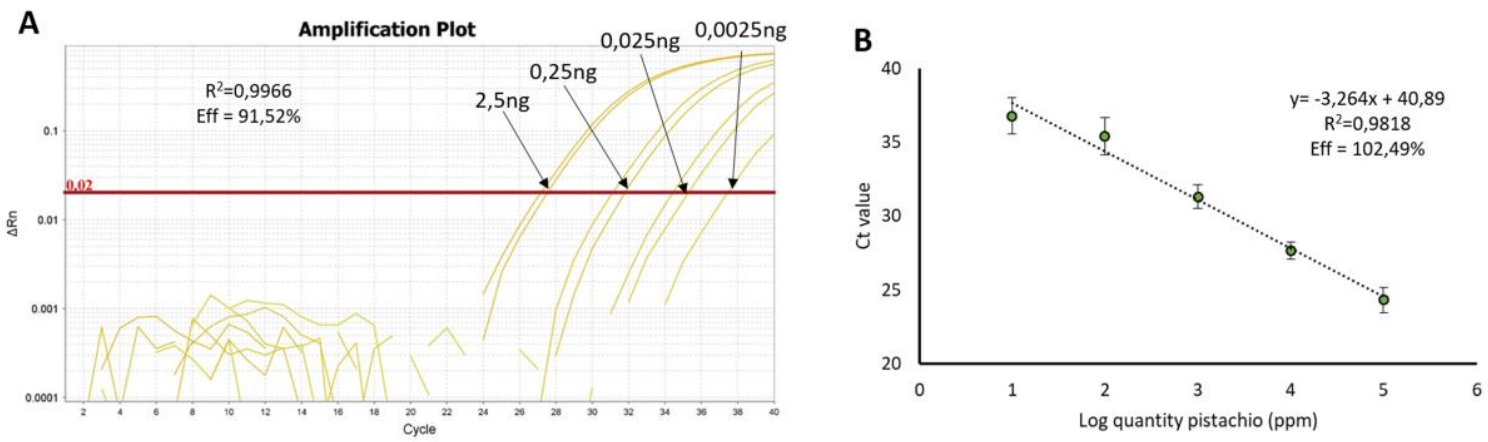

Figure 3. Performance of the amplification reaction for the detection of Pis v 1 target. A) Amplification plot of the calibration curve made from a serial dilution of DNA from Aegina pistachio variety. B) Standard calibration curve built with DNA from binary mixtures of a known amount of pistachio in wheat, representing the log of the ppm $(\mathrm{mg} / \mathrm{kg})$ of pistachio in the wheat matrix vs Ct value.

Regarding the effect of DIC treatment at the particular conditions of 7 bar 120 seconds on Pis $\mathrm{v}$ 1 target, for the same spiked level (10 to $0.1 \%$ ) of the binary mixtures, $\mathrm{Ct}$ is significantly delayed compared to the untreated control, and linear regression is not obtained. In the case of $10 \%$ containing binary mixtures, the detection was delayed more than 10 cycles (Figure 4). Pis $\mathrm{v} 1$ target was not detectable when treated flour was present in less than $1 \% \mathrm{w} / \mathrm{w}$ in the wheat mixture (Figure $4)$.

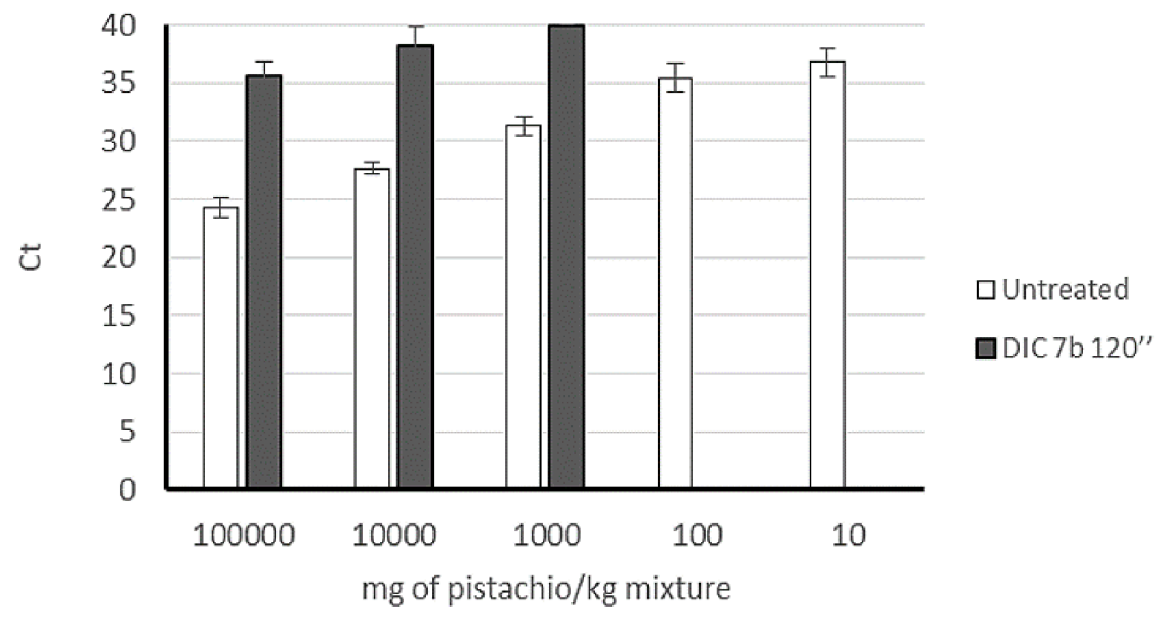

Figure 4. Amplification of Pis v 1 target in untreated (white column, $\mathrm{N}=8$ ) and treated (black column, $\mathrm{N}=10$ ) mixtures in the wheat matrix, representing the quantity of pistachio in $\mathrm{mg} / \mathrm{kg}$ of mixture vs $\mathrm{Ct}$ value.

This result is similar to the effect produced on the detectability of Pis $\mathrm{v} 1$ when pistachio nuts were submitted to heat and pressure in an autoclave on Pis $\mathrm{v} 1$ amplificability was noticeable and similar to the effect observed after treatment with DIC, which also combines heat and pressure. A direct comparison can be performed since sample preparation is equivalent for all treatments. This comparison is detailed in Figure 5, where can be observed that no significant differences between $\mathrm{Ct}$ values from DIC $7 \mathrm{~b} 2^{\prime}$ and $\mathrm{AU} 138^{\circ} \mathrm{C} 30$ min treated samples were found. 


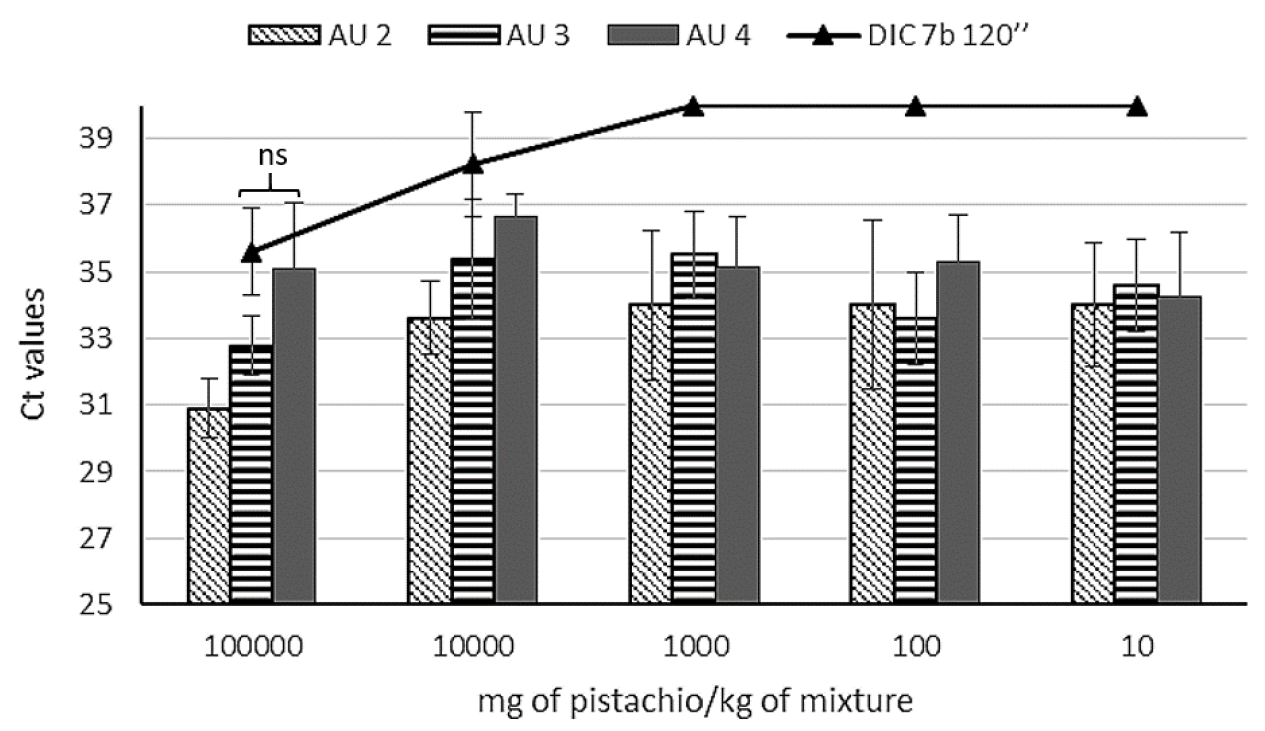

Figure 5. Amplification of Pis v 1 target in binary mixtures of flours treated by DIC $7 \mathrm{~b} 120$ sec (line), obtained in this work, and other treated samples by heat and pressure (autoclave: AU $2\left(121^{\circ} \mathrm{C}, 1.18\right.$ atm, $30 \mathrm{~min}$ ); $\mathrm{AU} 3\left(138^{\circ} \mathrm{C}\right.$ and $2.56 \mathrm{~atm}$ for $15 \mathrm{~min}$ ); $\mathrm{AU} 4$ (138 ${ }^{\circ} \mathrm{C}$ and $2.56 \mathrm{~atm}$ for $30 \mathrm{~min}$ ) (data from [19]). "ns" means that no significant differences were found between Ct obtained in DIC and AU 4 samples ( $\mathrm{p}<0.05$, by $\mathrm{t}$-student test).

Recently, Vicente and collaborators [27] showed the effect of this same DIC 7b, 120s treatment, on in vitro IgE binding capacity of pistachio, testing sera from Spanish allergic patients. By mass spectrometry, authors showed that major allergens (Pis v 1 and Pis v 2) survived this treatment, being some of them able to trigger IgE immunoreactivity in several patients. Even though, this treatment allows to importantly reduce the capacity to bind IgG and IgE antibodies of pistachio. With the Realtime PCR method we present here, it would be possible to detect traces of treated pistachio by DIC $7 \mathrm{~b} 120 \mathrm{sec}$ (above $1000 \mathrm{ppm}$ ).

\subsection{Effect of DIC treatment on cashew detectability}

Finally, the influence of this treatment on the amplification of the target Ana o 1 from cashew was studied. Previously [20], we optimised a methodology for the specific and sensitive detection of cashew in complex mixtures, by means of Real-time PCR and using a hydrolysis probe (Table 1). Two standard calibration curves were built from the $\mathrm{Ct}$ values and the log of the cashew quantity. Both curves showed good performance, with parameters of $\mathrm{R}^{2}$ and efficiency of reaction within the minimal standards for Real-time PCR publications (efficiency between 90 and $110 \%, R^{2}>0.99$ [28]) (Figure 6).

A

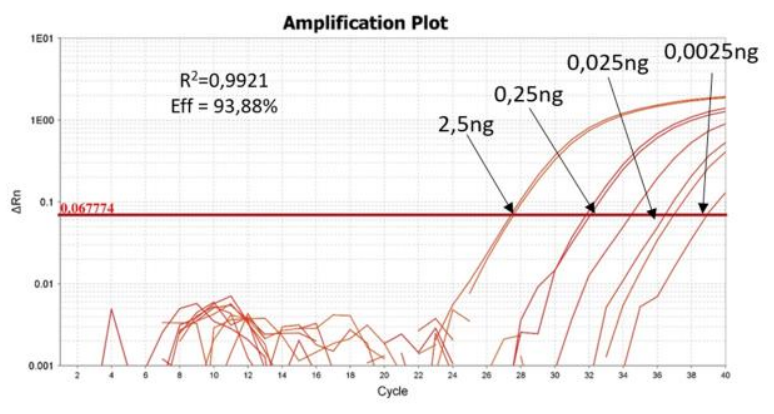

B

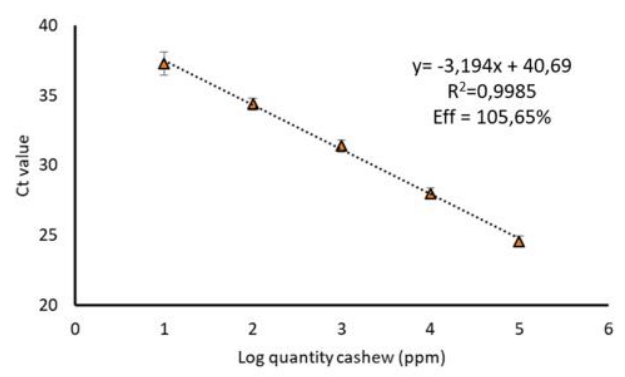

Figure 6. Performance of the amplification reaction for the detection of Ana o 1 target. A) Amplification plot of the calibration curve made from a serial dilution of DNA from cashew type 320. 
B) Standard calibration curve built with DNA from binary mixtures of a known amount of cashew in wheat, representing the log of the ppm $(\mathrm{mg} / \mathrm{kg})$ of cashew in the wheat matrix vs $\mathrm{Ct}$ value $(\mathrm{N}=8)$.

Achieved absolute and practical LODs were $2.5 \mathrm{pg}$ of cashew DNA and $10 \mathrm{ppm}$ of cashew flour in the wheat matrix, in concordance with the available data. Specificity was previously assayed by Sanchiz et al [19]. Figure 7 shows the general effect of DIC treatment, at $7 \mathrm{~b}$ for $120 \mathrm{sec}$, on the detection of Ana o 1 target, compared to control. Again, $\mathrm{Ct}$ is significantly delayed compared to the untreated control, up to 7 cycles in the $10 \%$-containing cashew mixture, although with an important lower impact that pistachio and especially hazelnut (Figure S3). However, standard curve built with log quantity of treated cashew (ppm, just three points) vs $\mathrm{Ct}$ values maintained good performance with $\mathrm{R}^{2}=0.9955$ and efficiency of the reaction of $108,84 \%$. Thus, detection and even quantification of the target Ana o 1 was possible even in the samples containing up to $1000 \mathrm{ppm}$ of DIC treated cashew flour, in 9 out to 10 replicates.

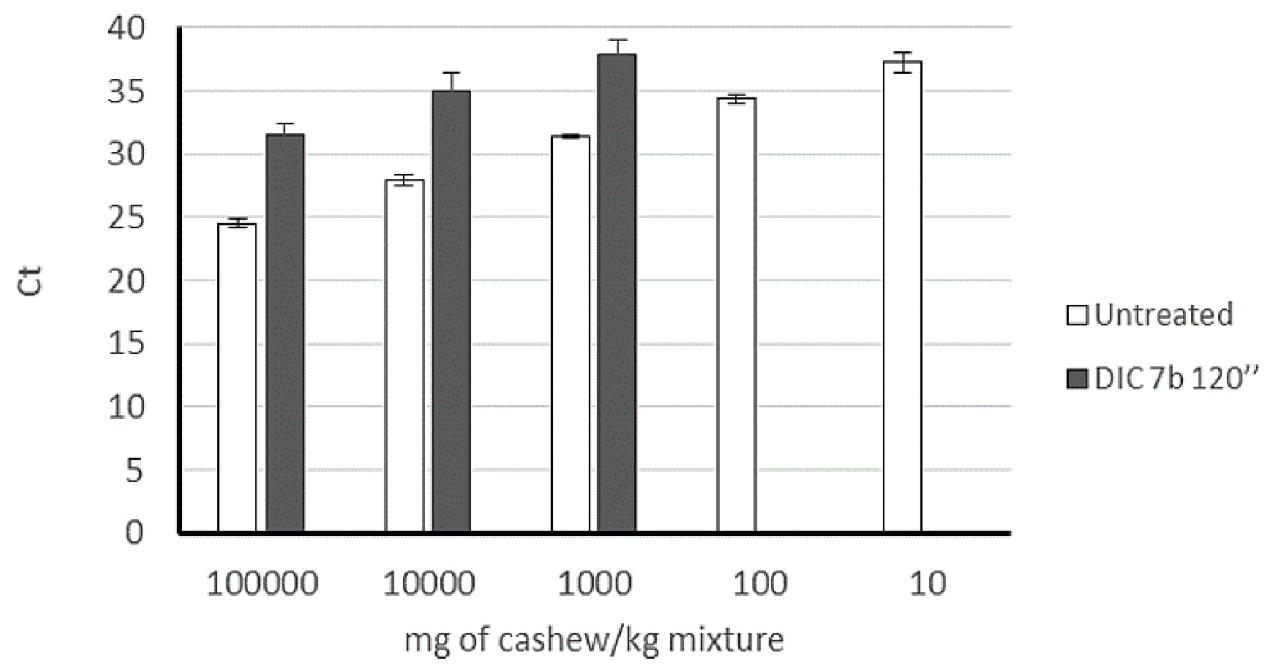

Figure 7. Amplification of Ana o 1 target in untreated (white column, $\mathrm{N}=8$ ) and treated (black column, $\mathrm{N}=10$ ) mixtures in a wheat matrix, representing the quantity of cashew in $\mathrm{mg} / \mathrm{kg}$ of mixture vs $\mathrm{Ct}$ value.

As recently reviewed [3], small amplicon size ( $<150 \mathrm{bp})$ is desired since DNA from foodstuff is usually fragmented and it could affect the detectability of the target. In the method for Ana o 1, it was observed an improvement compared to other studies that also considered allergen-coding sequences as a target, probably due to the small size of the amplicon, of only $65 \mathrm{bp}$. This particular method was very sensitive for cashew detection when it was subjected to heat and pressure at harsh conditions. At $138^{\circ} \mathrm{C}$ for 15 minutes in autoclave, the detection and quantification were possible up to $1000 \mathrm{mg}$ per $\mathrm{kg}$ of the mixture, maintaining a linear correlation of the curve (from $10^{5}$ to $1000 \mathrm{ppm}$ ), similarly to DIC treatment at 7 bar for $120 \mathrm{~s}$, with no significant differences between both treatments (Figure $8)$. 


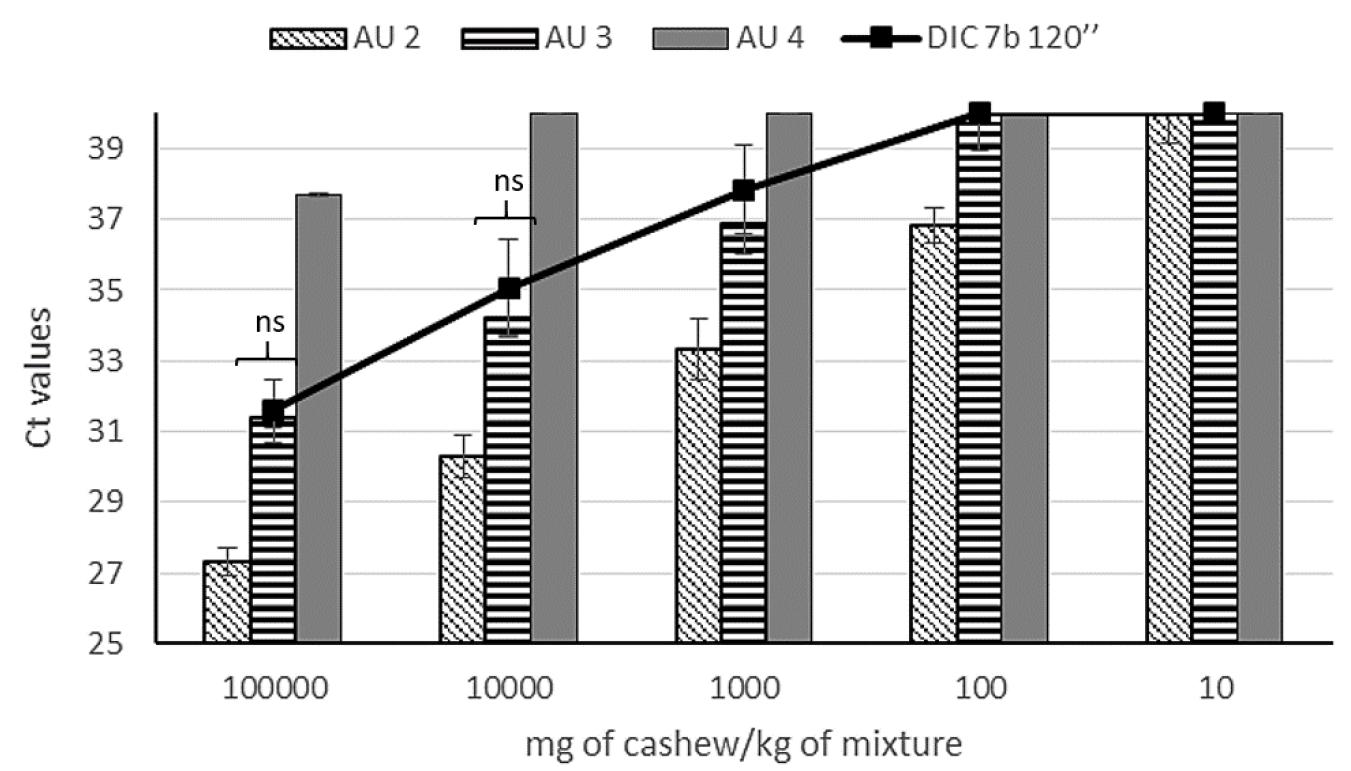

Figure 8. Amplification of Ana o 1 target in binary mixtures of flours treated by DIC $7 \mathrm{~b} 120 \mathrm{sec}$ (line), obtained in this work, and other treated samples by heat and pressure (autoclave: AU $2\left(121^{\circ} \mathrm{C}, 1.18\right.$ atm, $30 \mathrm{~min}$ ); $\mathrm{AU} 3$ ( $138^{\circ} \mathrm{C}$ and $2.56 \mathrm{~atm}$ for $\left.15 \mathrm{~min}\right)$; $\mathrm{AU} 4$ (138 ${ }^{\circ} \mathrm{C}$ and $2.56 \mathrm{~atm}$ for $30 \mathrm{~min}$ ) (data from [20]). "ns" means that no significant differences were found between Ct obtained in DIC and AU 3 samples $(\mathrm{p}<0.05$, by t-student test).

As mentioned with pistachio, Vicente and collaborators [27] showed for the first time, by mass spectrometry, that major cashew allergens (Ana o 2 and Ana o 3) survived to DIC $7 \mathrm{~b} 120 \mathrm{sec}$ processing, and triggered $\operatorname{IgE}$ immunoreactivity in patients, although reduction of the capacity to bind IgE antibodies was noticeable. This tested Real-time PCR assays, especially in the case of cashew, would allow to potentially detect traces of the nuts treated by heat and pressure at 7 bar and 2 minutes, which resulted in the appearance of an immunoreactive response in sensitive patients. In that study [27], pistachio proteins also resulted more susceptible to DIC processing than cashew ones, and, according to our results, it was possible to detect and quantify with good efficiency treated cashew, better than pistachio (Figure S3).

Interestingly, the effect of food processing on the capacity to detect traces of a particular allergen is not always deeply studied. As stated before, thermal treatments, with or without combination of pressure, has a different effect depending on the material, whereas non-thermal treatments, such as HHP, generally resulted to produce few impact on the detectability of nut targets, as in almond and walnut $[29,30]$. In general, among thermal treatments, those that combine heat and pressure are responsible for more fragmentation of DNA and make it difficult to amplify the targets in nuts; apart from hazelnut, pistachio and cashew, it has been also demonstrated in walnut, almond, and chestnut $[22,29,30]$. Treatment based on Instantaneous Controlled Pressure Drop (DIC) on foods and its effect on allergenicity has not been extensively analysed. Together with the recent study in cashew and pistachio [27], already discussed, are mentionable the studies about the influence of this treatment on the IgE reactivity of legumes and milk [31,32]. In the case of legumes [12,32], the application of DIC treatment at 6 bar for 3 min did not eliminate the immunoreactive capacity of peanut, chickpea and lentil allergens, but in the case of soybeans and lupin, it was markedly reduced.

\section{Conclusions}

As far as we know, this is the first work studying the effect of DIC treatment, which combines heat and pressure, for a very short time, on the detectability of a DNA target by Real-time PCR, using hydrolysis probes. We confirmed that the application of pressure, 7 bar and temperature, up to 180 ${ }^{\circ} \mathrm{C}$, for only $2 \mathrm{~min}$, on tree nut seeds, can reduce the ability to detect allergen-coding sequences from hazelnut (Cor a 9), pistachio (Pis v 1) and cashew (Ana o 1). This effect was less intense in the case of 
cashew allergen. According to the available data regarding the effect of DIC processing on the IgG/IgE binding capacity of nuts, this system would allow detecting traces of DIC 7 b-120 sec processed hazelnut and pistachio, and even quantify treated cashew, if the quantity of the allergenic ingredient is around $10-1 \% \mathrm{w} / \mathrm{w}$ in a food mixture.

Supplementary Materials: The following are available online at www.mdpi.com/xxx/s1, Figure S1: Partial alignment of Pis v 1, Ana o 1 and Cor a 9 coding sequences. Figure S2: Amplification of Cor a 9 target in untreated and treated samples included in wheat or peanut binary mixtures. Figure S3: Relative detection of Pis v 1, Ana o 1 and Cor a 9 targets.

Author Contributions: "Conceptualization, C.C. and R.L.; methodology, A.S.; J.H; validation, A.S.; formal analysis, A.S., C.C., R.L.; investigation, A.S., C.C., R.L..; resources, C.C., R.L..; data curation, A.S.; writingoriginal draft preparation, A.S.; writing - review and editing, C.C; R.L.; supervision, R.L.; project administration, C.C..; funding acquisition, C.C.. All authors have read and agreed to the published version of the manuscript.

Funding: This research was funded by the Spanish Ministerio de Ciencia e Innovación, grant number AGL2017-83082-R.

Conflicts of Interest: The authors declare no conflict of interest.

\section{References}

1. Sicherer, S.H. Evaluation of Food Allergy. In Mount Sinai Expert Guides: Allergy and Clinical Immunology; Sampson, H.A., Ed.; 2015; pp. 132-139.

2. Ojeda, P.; Sastre, J.; Jm, O.; Chivato, T. Alergólogica 2015: A National Survey on Allergic Diseases in the Adult Spanish Population. J. Investig. Allergol. Clin. Immunol. 2018, 28, 151-164.

3. Linacero, R.; Sanchiz, A.; Ballesteros, I.; Cuadrado, C. Application of real-time PCR for tree nut allergen detection in processed foods. Crit. Rev. Food Sci. Nutr. 2020, 60, 1077-1093.

4. Crespo, J.F.; James, J.M.; Fernandez-Rodriguez, C.; Rodriguez, J. Food allergy: Nuts and tree nuts. Br. J. Nutr. 2006, 96, 95-102.

5. Van Der Valk, J.P.M.; J. Dubois, A.E.; Gerth Van Wijk, R.; Wichers, H.J.; De Jong, N.W. Systematic review on cashew nut allergy. Allergy Eur. J. Allergy Clin. Immunol. 2014, 69, 692-698.

6. Noorbakhsh, R.; Mortazavi, S.A.; Sankian, M.; Shahidi, F.; Tehrani, M.; Jabbari Azad, F.; Behmanesh, F.; Varasteh, A. Pistachio Allergy-Prevalence and In vitro Cross-Reactivity with Other Nuts. Allergol. Int. 2011, $60,425-432$.

7. Cabanillas, B.; Novak, N. Effects of daily food processing on allergenicity. Crit. Rev. Food Sci. Nutr. 2017, 11, $1-12$.

8. Sanchiz, A.; Cuadrado, C.; Dieguez, M.C.; Ballesteros, I.; Rodriguez, J.; Crespo, J.F.; de las Cuevas, N.; Rueda, J.; Linacero, R.; Cabanillas, B.; et al. Thermal processing effects on cashew and pistachio allergenicity. Food Chem. 2018, 245, 595-602.

9. Cuadrado, C.; Cheng, H.; Sanchiz, Á.; Ballesteros, I.; Easson, M.; Grimm, C.C.; Dieguez, M. del C.; Linacero, R.; Burbano, C.; Maleki, S.J. Influence of enzymatic hydrolysis on the allergenic reactivity of processed cashew and pistachio. Food Chem. 2018, 241, 372-379.

10. Haddad, J.; Louka, N.; Gadouleau, M.; Juhel, F.; Allaf, K. Application du nouveau procédé de séchage/texturation par Détente Instantanée Contrôlée DIC aux poissons: Impact sur les caractéristiques physico-chimiques du produit fini. Sci. des Aliment. 2001, 21, 481-498.

11. Cuadrado, C.; Cabanillas, B.; Pedrosa, M.M.; Muzquiz, M.; Haddad, J.; Allaf, K.; Rodriguez, J.; Crespo, J.F.; Burbano, C. Effect of instant controlled pressure drop on ige antibody reactivity to peanut, lentil, chickpea and soybean proteins. Int. Arch. Allergy Immunol. 2011, 156, 397-404.

12. Guillamon, E.; Burbano, C.; Cuadrado, C.; Muzquiz, M.; Pedrosa, M.M.; Sanchez, M.; Cabanillas, B.; Crespo, J.F.; Rodriguez, J.; Haddad, J.; et al. Effect of an instantaneous controlled pressure drop on in vitro allergenicity to lupins (Lupinus albus var Multolupa). Int Arch Allergy Immunol 2008, 145, 9-14.

13. Cuadrado, C.; Sanchiz, A.; Vicente, F.; Ballesteros, I.; Linacero, R. Changes Induced by Pressure Processing on Immunoreactive Proteins of Tree Nuts. Molecules 2020, 25, 954-965.

14. Cabanillas, B.; Maleki, S.J.; Rodríguez, J.; Burbano, C.; Muzquiz, M.; Jiménez, M.A.; Pedrosa, M.M.; Cuadrado, C.; Crespo, J.F. Heat and pressure treatments effects on peanut allergenicity. Food Chem. 2012, 132, 360-366. 
15. Vanga, S.K.; Raghavan, V. Processing Effects On Tree Nut Allergens: A Review. Crit. Rev. Food Sci. Nutr. 2016, 57, 3794-3806.

16. Alves, R.C.; Barroso, M.F.; González-García, M.B.; Oliveira, M.B.P.P.; Delerue-Matos, C. New Trends in Food Allergens Detection: Toward Biosensing Strategies. Crit. Rev. Food Sci. Nutr. 2016, 56, 2304-2319.

17. de la Cruz, S.; Lopez-Calleja, I.; Martin, R.; Gonzalez, I.; Alcocer, M.; Garcia, T. Recent advances in the detection of allergens in foods. In Food Allergens: Methods and Protocols, Methods in Molecular Biology.; Lin, J., Alcocer, M., Eds.; Springer Science, 2017; Vol. 1592, pp. 263-295 ISBN 978-1-4939-6923-4.

18. Hird, H.; Chisholm, J.; Sanchez, A.; Hernandez, M.; Goodier, R.; Schneede, K.; Boltz, C.; Popping, B. Effect of heat and pressure processing on DNA fragmentation and implications for the detection of meat using a real-time polymerase chain reaction. Food Addit. Contam. 2006, 23, 645-650.

19. Sanchiz, A.; Ballesteros, I.; Martin, A.; Rueda, J.; Pedrosa, M.M.; Dieguez, M. del C.; Rovira, M.; Cuadrado, C.; Linacero, R. Detection of pistachio allergen coding sequences in food products: A comparison of two real time PCR approaches. Food Control 2017, 75, 262-270.

20. Sanchiz, A.; Ballesteros, I.; Marqués, E.; Dieguez, M.C.; Rueda, J.; Cuadrado, C.; Linacero, R. Evaluation of locked nucleic acid and TaqMan probes for specific detection of cashew nut in processed food by real time PCR. Food Control 2018, 89, 227-234.

21. Iniesto, E.; Jimenez, A.; Prieto, N.; Cabanillas, B.; Burbano, C.; Pedrosa, M.M.; Rodriguez, J.; Muzquiz, M.; Crespo, J.F.; Cuadrado, C.; et al. Real Time PCR to detect hazelnut allergen coding sequences in processed foods. Food Chem 2013, 138, 1976-1981.

22. Sanchiz, A.; Ballesteros, I.; López-García, A.; Ramírez, A.; Rueda, J.; Cuadrado, C.; Linacero, R. Chestnut allergen detection in complex food products: Development and validation of a real-time PCR method. LWT - Food Sci. Technol. 2020, 123.

23. Bustin, S.A. Why the need for qPCR publication guidelines?-The case for MIQE. Methods 2010, 50, $217-226$.

24. Costa, J.; Oliveira, M.B.P.P.; Mafra, I. Effect of thermal processing on the performance of the novel singletube nested real-time PCR for the detection of walnut allergens in sponge cakes. Food Res. Int. 2013, 54, $1722-1729$.

25. Villa, C.; Costa, J.; Gondar, C.; Oliveira, M.B.P.P.; Mafra, I. Effect of food matrix and thermal processing on the performance of a normalised quantitative real-time PCR approach for lupine (Lupinus albus) detection as a potential allergenic food. Food Chem. 2018, 262, 251-259.

26. Lopez, E.; Cuadrado, C.; Burbano, C.; Jimenez, M.A.; Rodriguez, J.; Crespo, J.F. Effects of autoclaving and high pressure on allergenicity of hazelnut proteins. J Clin Bioinforma 2012, 2, 2043-9113.

27. Vicente, F.; Sanchiz, A.; Rodriguez, R.; Pedrosa, M.; Quirce, S.; Haddad, J.; Besombes, C.; Linacero, R.; Allaf, K.; Cuadrado, C. Influence of Instant Controlled Pressure Drop ( DIC ) on Allergenic Potential of Tree Nuts. Molecules 2020, 4 .

28. Bustin, S.A.; Beaulieu, J.F.; Huggett, J.; Jaggi, R.; Kibenge, F.S.B.; Olsvik, P.A.; Penning, L.C.; Toegel, S. MIQE précis: Practical implementation of minimum standard guidelines for fluorescence-based quantitative real-time PCR experiments. BMC Mol. Biol. 2010, 11.

29. Prieto, N.; Iniesto, E.; Burbano, C.; Cabanillas, B.; Pedrosa, M.M.; Rovira, M.; Rodr??guez, J.; Muzquiz, M.; Crespo, J.F.; Cuadrado, C.; et al. Detection of almond allergen coding sequences in processed foods by real time PCR. J. Agric. Food Chem. 2014, 62, 5617-5624.

30. Linacero, R.; Ballesteros, I.; Sanchiz, Á.; Prieto, N.; Elisa, I.; Martinez, Y.; Pedrosa, M.; Muzquiz, M.; Cabanillas, B.; Rovira, M.; et al. Detection by Real Time PCR of Walnut Allergen Coding Sequences in Processed Foods. Food Chem. 2016, 202, 334-340.

31. Boughellout, H.; Choiset, Y.; Rabesona, H.; Chobert, J.M.; Haertle, T.; Mounir, S.; Allaf, K.; Zidoune, M.N. Effect of instant controlled pressure drop (DIC) treatment on milk protein's immunoreactivity. Food Agric. Immunol. 2015, 26, 71-81.

32. Takács, K.; Guillamon, E.; Pedrosa, M.M.; Cuadrado, C.; Burbano, C.; Muzquiz, M.; Haddad, J.; Allaf, K.; Maczó, A.; Polgár, M.; et al. Study of the effect of instant controlled pressure drop (DIC) treatment on IgEreactive legume-protein patterns by electrophoresis and immunoblot. Food Agric. Immunol. 2014, 25, 173185. 